\title{
Effect of Nb Addition on Cu Precipitation in Ferritic Stainless Steel
}

\author{
Sengo KOBAYASHI, ${ }^{1)}$ Takafumi TAKEDA, ${ }^{1)}$ Kiyomichi NAKAI, ${ }^{1)}$ Jun-ichi HAMADA, ${ }^{2)}$ Norihiro KANNO ${ }^{3)}$ \\ and Tatsuaki SAKAMOTO'1) \\ 1) Department of Materials Science and Biotechnology, Ehime University, 3 Bunkyo-cho, Matsuyama, $790-8577$ Japan. \\ 2) Nippon Steel Corporation, Steel Research Laboratories, 20-1 Shintomi, Futtsu, 293-8511 Japan \\ 3) Nippon Steel \& Sumikin Stainless Steel Corporation, Research \& Development Center, 3434 Shimata, Hikari, $743-8550$ Japan.
}

(Received on September 28, 2010; accepted on January 5, 2011)

\begin{abstract}
Formations of Cu-rich precipitate in $18 \% \mathrm{Cr}-1.5 \% \mathrm{Cu}$ stainless steels without and with $0.5 \% \mathrm{Nb}$ have been examined mainly using transmission electron microscopy. The specimens solution-treated at $1250^{\circ} \mathrm{C}$ were isothermally transformed at various temperatures between 500 and $850^{\circ} \mathrm{C}$. Fine spherical Cu-rich solute zones were nucleated in the steels in the beginning of aging. These Cu-rich zones exhibited bcc structure and then transformed into 9R structure with twins during aging. The spherical 9R-Cu particles changed into rod-shaped fcc-Cu particles after prolonged aging. Laves phase of $\mathrm{Fe}_{2} \mathrm{Nb}$ type started to form in the $\mathrm{Nb}$-added steel almost after finishing nucleation and growth of $\mathrm{Cu}$ particles. Addition of $\mathrm{Nb}$ in the steel delayed the nucleation of the Cu-rich zones due to slow diffusion of $\mathrm{Nb}$ atoms in ferrite.
\end{abstract}

KEY WORDS: ferritic stainless steel; Cu precipitation; Nb addition; transmission electron microscopy (TEM).

\section{Introduction}

As for the $\mathrm{Cu}$ containing steels, it is well known that strength, high temperature strength and fatigue strength are improved by $\mathrm{Cu}$ precipitation. ${ }^{1-4)}$ And, as well as a study about the $\mathrm{Cu}$ precipitation behavior, ${ }^{5)}$ its effects to the texture and formability have been reported. ${ }^{6-8)}$ According to the published phase diagrams of $\mathrm{Fe}-\mathrm{Cu}$ binary system, the maximum solubility of copper in ferrite is $2.2 \mathrm{mass} \%$ at $850^{\circ} \mathrm{C}$. ${ }^{9)}$ The solubility of copper in ferrite, $\mathrm{c}^{\alpha}$, is expressed as $\log \left[\mathrm{c}^{\alpha}\right]=-4500 / \mathrm{T}+4.335$, e.g. $\mathrm{c}^{\alpha}=0.5$ and 0.03 mass $\%$ at 700 and $500{ }^{\circ} \mathrm{C}$, respectively. ${ }^{10)}$ Small solubility of $\mathrm{Cu}$ in ferrite leads to the formation of $\mathrm{Cu}$ particles during aging in $\mathrm{Cu}$ added steels. Process of $\mathrm{Cu}$ precipitation in ferrite has been reported as follows; (i) nucleation of the coherent spherical Cu-rich zones with bcc structure, ${ }^{11-16)}$ (ii) transformation of bec $\mathrm{Cu}$-rich zones into multi-twinned particles with 9R structure, ${ }^{17,18)}$ and (iii) transformation of 9R Cu-rich particles into fcc- $\mathrm{Cu}$ particles with shape change from sphere to rod. ${ }^{11)}$ The shape change of $\mathrm{Cu}$ particle from sphere to rod is associated with coherency loss. ${ }^{19,20)}$ Precipitation of $\mathrm{Cu}$ particles in stainless steels can also be found in the literature. ${ }^{21-26)}$ Soylu and Honeycombe studied formation of $\mathrm{Cu}$ precipitates in a duplex stainless steel. ${ }^{21)}$ They reported that first stage of $\mathrm{Cu}$ precipitation in ferrite was the formation of bcc coherent $\mathrm{Cu}$-rich zones and bcc $\mathrm{Cu}$-rich zones transformed to fcc $\mathrm{Cu}$ particles. Formation of $\mathrm{Cu}$ particles in a PH 15-5 stainless steel was studied in detail by Habibi Bajguirani et al. ${ }^{22-24)}$ They showed that $\mathrm{Cu}$-rich precipitation in a PH 15-5 began with the formation of coherent bcc clusters which subsequently transformed to twinned 9R, $3 \mathrm{R}$ and fcc-Cu particles. Murayama et al. ${ }^{25)}$ reported that the chemical composition of the bcc $\mathrm{Cu}$-rich clusters in a PH17-
4 stainless steel has been found to be $55 \mathrm{at} \% \mathrm{Cu}, 30 \mathrm{at} \% \mathrm{Fe}$, $10 \mathrm{at} \% \mathrm{Cr}$ and $5 \mathrm{at} \% \mathrm{Ni}$. Rejection of $\mathrm{Fe}, \mathrm{Cr}$ and $\mathrm{Ni}$ from $\mathrm{Cu}-$ rich cluster occurred during aging and concentration of coarsened fcc-Cu particles was almost $100 \mathrm{at} \% \mathrm{Cu}$. $\mathrm{Cu}$ addition in stainless steels is also utilized from the viewpoints of corrosion resistance ${ }^{27)}$ and antimicrobial activity. ${ }^{28)}$ In addition, there is a case to add $\mathrm{Nb}$ to obtain superior corrosion resistance and mechanical properties in ferritic stainless steels. Niobium in ferritic stainless steels is known as a beneficial element to increase high temperature strength. ${ }^{29-31)}$ Fujita et al. showed that an increase in $0.2 \%$ proof strength of a ferritic $19 \% \mathrm{Cr}$ steel at $950^{\circ} \mathrm{C}$ by $\mathrm{Nb}$ addition is much greater than those by other elements such as $\mathrm{Si}, \mathrm{P}, \mathrm{Ti}, \mathrm{Mo}$, $\mathrm{W}$, Hf and $\mathrm{Ta}^{29)}$ They suggested that increase in strength caused by $\mathrm{Nb}$ addition is mainly due to solid solution strengthening. Although there are many studies on the effects of $\mathrm{Cu}$ or $\mathrm{Nb}$ additions on the phase transformation and mechanical properties in steels, the effect of $\mathrm{Nb}$ addition on the formation of $\mathrm{Cu}$ precipitates in a ferritic stainless steel has not been well understood. The purpose of the present study, therefore, is to reveal the effect of $\mathrm{Nb}$ addition on $\mathrm{Cu}$ precipitation in a $18 \% \mathrm{Cr}$ ferritic stainless steel.

\section{Experimental Procedures}

Ferritic stainless steel sheets marked with E1, E2 and E3, of $2 \mathrm{~mm}$ thick manufactured in the laboratory were used. The chemical compositions of the steels in mass $\%$ are shown in Table 1. The steels are based on a $18 \% \mathrm{Cr}$ stainless steel with low impurities. The E1 and E2 steels contain $0.48 \% \mathrm{Nb}$ and $1.53 \% \mathrm{Cu}$, respectively. Both $0.47 \% \mathrm{Nb}$ and $1.57 \% \mathrm{Cu}$ are contained in E3 steel. Specimens in $10 \mathrm{~mm}$ wide and $10 \mathrm{~mm}$ long were machined from the steels. They 
Table 1. Chemical compositions of the steels used in the present study (in mass \%).

\begin{tabular}{cccccccccccccccc}
\hline No & $\mathrm{C}$ & $\mathrm{Si}$ & $\mathrm{Mn}$ & $\mathrm{P}$ & $\mathrm{S}$ & $\mathrm{Ni}$ & $\mathrm{Cr}$ & $\mathrm{Mo}$ & $\mathrm{Cu}$ & $\mathrm{Ti}$ & $\mathrm{Al}$ & $\mathrm{Nb}$ & $\mathrm{O}$ & $\mathrm{N}$ \\
\hline E1 & 0.002 & 0.04 & 0.01 & 0.01 & 0.0009 & 0.1 & 18.4 & 0.01 & 0.01 & 0.05 & 0.04 & 0.48 & 0.0036 & 0.004 \\
E2 & 0.001 & 0.03 & 0.01 & 0.01 & 0.0006 & 0.1 & 18.4 & 0.01 & 1.53 & 0.05 & 0.04 & 0.02 & 0.0085 & 0.004 \\
E3 & 0.002 & 0.06 & 0.01 & 0.01 & 0.0007 & 0.1 & 18.4 & 0.01 & 1.57 & 0.05 & 0.04 & 0.47 & 0.0057 & 0.004
\end{tabular}
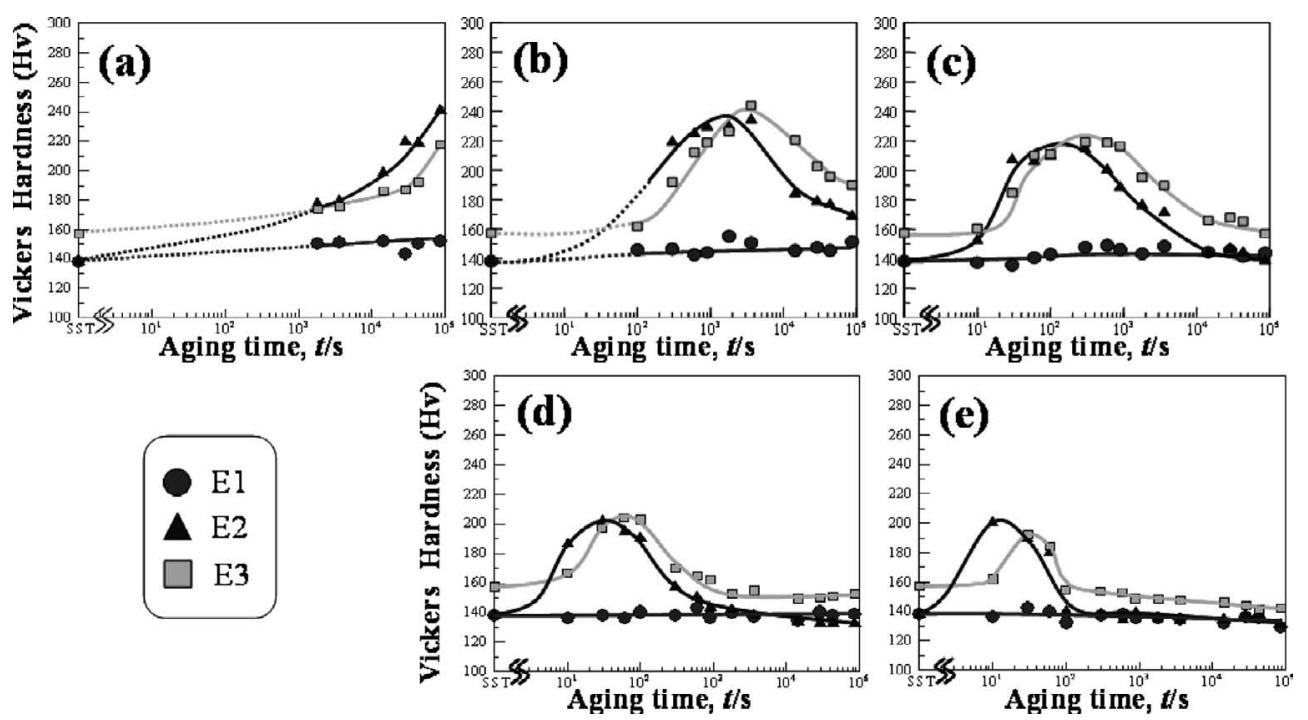

Fig. 1. Vickers hardness change during aging at (a) 500, (b) 600, (c) 700, (d) 800 and (e) $850^{\circ} \mathrm{C}$. Circles, triangles and squares represent the results for the E1, E2 and E3 steels, respectively.

were solution-treated at $1250^{\circ} \mathrm{C}$ for $0.6 \mathrm{ks}$ and quenched into iced brine. Then, they were isothermally aged at various temperatures from 500 to $850^{\circ} \mathrm{C}$ for $0.01-86.4 \mathrm{ks}$. Thin foils for transmission electron microscopy (TEM) were prepared by twin-jet polishing technique using an electrolyte containing $90 \mathrm{vol} \%$ acetic acid and $10 \mathrm{vol} \%$ perchloric acid. They were examined in transmission electron microscopes, JEM100CX, JEM2100 equipped with energy dispersive spectroscopy (EDS) detector and JEM3010, operating at 100,200 and $300 \mathrm{kV}$, respectively. Hardness measurements were carried out on both solution-treated and aged specimens at room temperature under 500 gf load. Average hardness was calculated from five measuring points.

\section{Results}

\subsection{Vickers Hardness Measurements}

The age-hardening curves at temperatures between 500 and $850^{\circ} \mathrm{C}$ are shown in Fig. 1. Circles, triangles and squares in Fig. 1 represent results for E1, E2 and E3 steels, respectively. Average values of Vickers hardness (Hv) for E1 and E2 steels after solid solution treatment (SST) were the same as 138, while that for E3 steel was 19 higher than those for the other steels. The Hv of E1 steel hardly changed during aging at all temperatures examined. The Hv of E2 and E3 steels, on the other hand, exhibited a large increase followed by a decrease during aging. The increase in $\mathrm{Hv}$ began more quickly at higher aging temperatures. Peak hardness during aging was decreased as increasing in aging temperature. Furthermore, the peak hardness in E3 steel is almost the same as that in E2 steel, indicating an increase in $\mathrm{Hv}$ in $\mathrm{E} 3$ by aging is smaller than that in E2. The age-
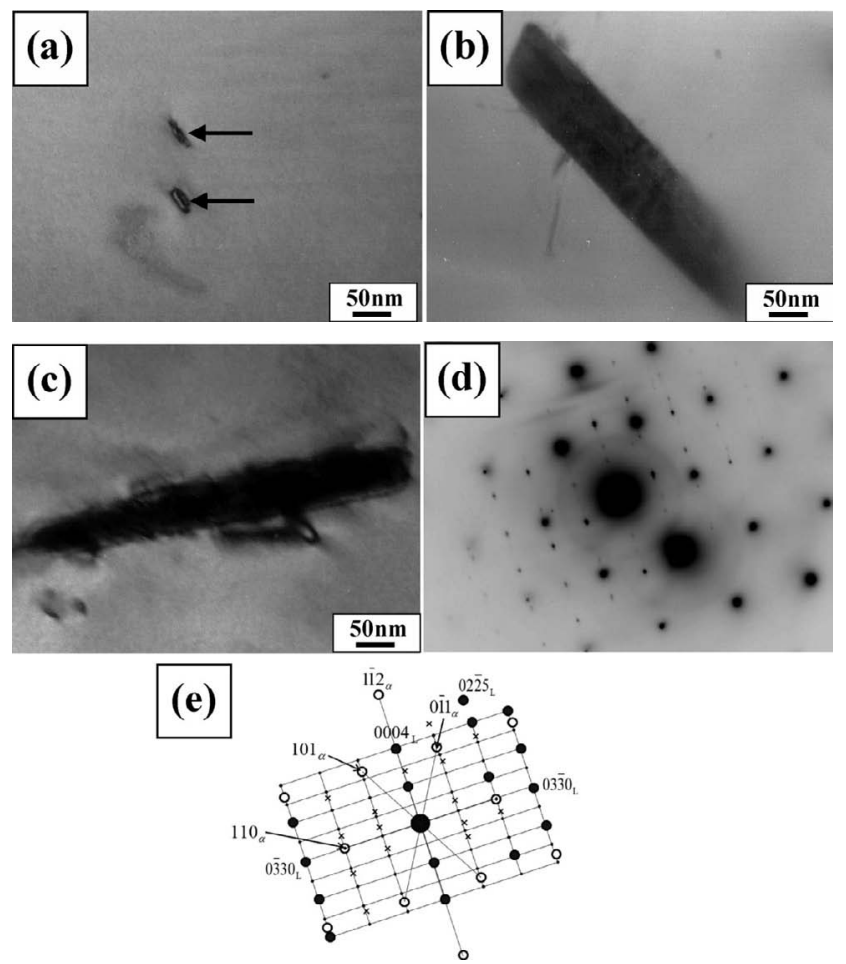

Fig. 2. TEM micrographs for the $\mathrm{E} 1$ steel aged at $700^{\circ} \mathrm{C}$ for (a) 0.9 and (b) $14.4 \mathrm{ks}$, respectively. Arrows in (a) indicate formation of plate-shaped precipitates. (c) TEM micrograph for the E1 steel aged at $700^{\circ} \mathrm{C}$ for $86.4 \mathrm{ks}$. Selected area diffraction pattern taken from Fig. 2(c) is shown in (d). Key diagram of Fig. 2(d) is illustrated in (e). Solid circles and open circles in (e) correspond to diffraction spots of Laves phase and ferrite matrix, respectively. Subscript letters $\alpha$ and $\mathrm{L}$ denote ferrite matrix and Laves phase, respectively. Cross marks indicate double or triple reflections. 
hardening curve in E3 steel shifted to the longer aging time. It implies that $\mathrm{Nb}$ addition in a $\mathrm{Cu}$-added ferritic stainless steel delays age-hardening behavior. Such the delay of increment in hardness by $\mathrm{Nb}$ addition in $\mathrm{Cu}$-added ferritic stainless steel can be found in all the temperature range examined.

\subsection{TEM Observations}

Figures 2(a), 2(b) and 2(c) show the bright field images taken from E1 steels aged at $700^{\circ} \mathrm{C}$ for $0.9,14.4$ and 86.4 ks, respectively. Selected area diffraction pattern (SAD) taken from Fig. 2(c) is shown in Fig. 2(d). Key diagram of Fig. 2(d) is illustrated in Fig. 2(e). Plate-shaped particles indicated by arrows in Fig. 2(a) started to form in the matrix after aging for $0.9 \mathrm{ks}$. The particles were coarsened by prolonged aging as shown in Figs. 2(b) and 2(c). Analysis of SAD shown in Fig. 2(d) reveals that the particles are $\mathrm{Fe}_{2} \mathrm{Nb}$ type Laves phase. The crystallographic orientation relationship between the Laves phase (L) and the ferrite matrix $(\alpha)$ is analyzed as $(1 \overline{1} 2)_{\alpha} / /(0001)_{\mathrm{L}}$ and $(110)_{\alpha} / /(01 \overline{1} 0)_{\mathrm{L}}$.

Bright field images of E2 steel aged at $700^{\circ} \mathrm{C}$ for 0.03 , 0.3, 1.8 and 86.4 ks are shown in Figs. 3(a) to 3(d), where the incident electron beam was adjusted to nearly parallel to the $[1 \overline{1} \overline{1}]_{\alpha}$ direction. Enlarged images of Figs. 3(a) and 3(b) are inserted in each figure. Fine spherical zones less than 10 $\mathrm{nm}$ in diameter as indicated by arrows were observed in Fig.
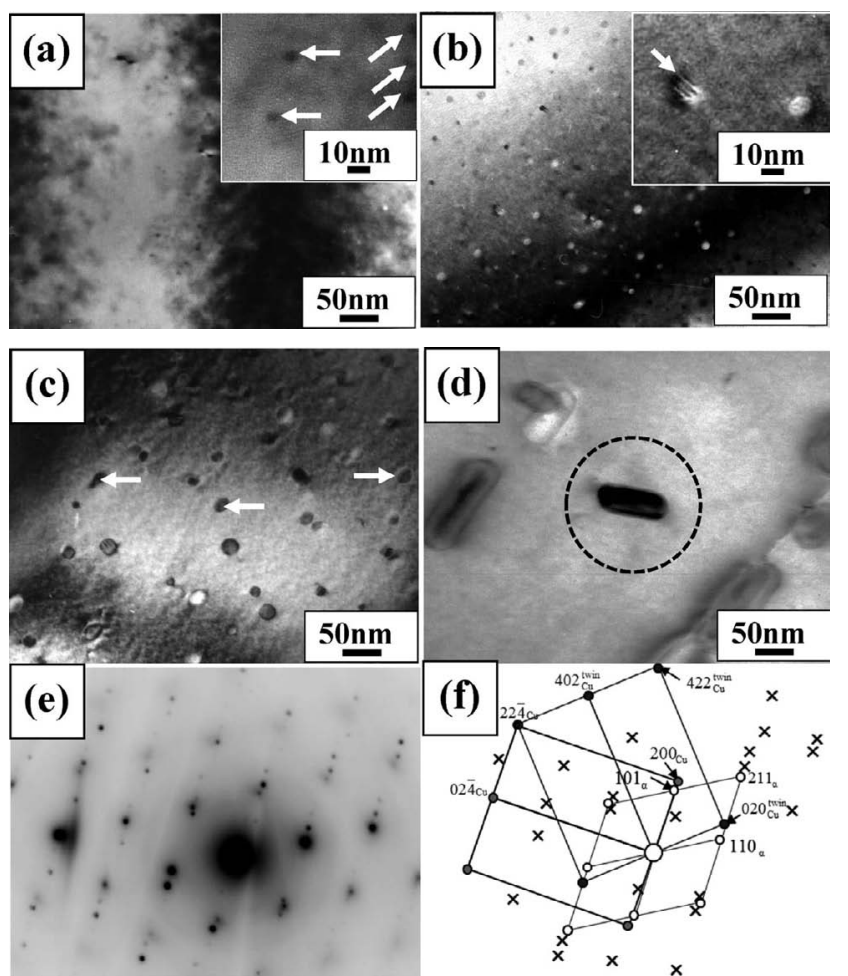

Fig. 3. TEM micrographs for the $\mathrm{E} 2$ steel aged at $700^{\circ} \mathrm{C}$ for (a) 0.03 and (b) $0.3 \mathrm{ks}$, respectively. TEM micrographs for the E2 steel aged at $700^{\circ} \mathrm{C}$ for (c) 1.8 and (d) $86.4 \mathrm{ks}$, respectively. Selected area diffraction pattern taken from a dotted circle area in Fig. 3(d) is shown in (e). Key diagram of Fig. 3(e) is illustrated in (f). Solid circles and open circles in (f) correspond to diffraction spots of fcc-Cu phase and ferrite matrix, respectively. Two $\mathrm{Cu}$ phase variants are observed and exhibit twin relationship. Subscript letters $\alpha$ and $\mathrm{Cu}$ denote ferrite matrix and fcc-Cu phase, respectively. Cross marks indicate double or triple reflections. 3(a). The spherical zones exhibited uniform contrast in the bright field image. Only diffraction spots from ferrite matrix could be detected in the SAD taken from Fig. 3(a). Growth of the spherical zones was observed in Fig. 3(b). Some of the spherical particles exhibited striped contrast parallel to $[110]_{\alpha}$ direction in the matrix as indicated by an arrow. Coarsening of spherical particles was observed in Fig. 3(c). Some of spherical particles started to change their shape into rod as indicated by arrows in Fig. 3(c). After aging for 86.4 ks, all particles became coarse rod-shaped as shown in Fig. 3(d). The SAD taken from a dotted circle area in Fig. 3(d) is shown in Fig. 3(e). Key diagram of Fig. 3(e) is illustrated in Fig. 3(f). Analysis of the SAD revealed that the rodshaped particles exhibited fcc structure with near KurdjumovSachs (K-S) orientation relationship with the matrix. The fcc-Cu particle analyzed in Fig. 3(d) exhibited $\{111\}$ fcc twin variants, which can be known from stereographical analysis of Fig. 3(f). Condensation of copper was detected by composition analysis of the rod-shaped particles by EDS. Therefore, formations of the spherical zones, the spherical

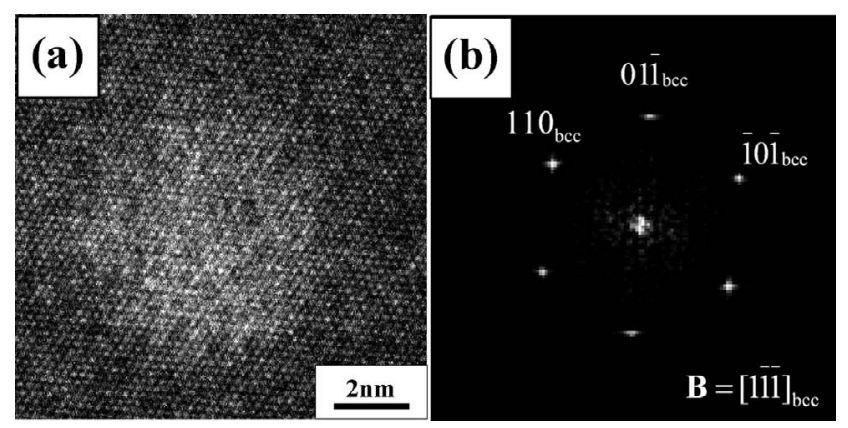

Fig. 4. (a) High resolution TEM image for the E2 steel aged at $700^{\circ} \mathrm{C}$ for $0.03 \mathrm{ks}$. (b) the Fourier transformed pattern of (a).

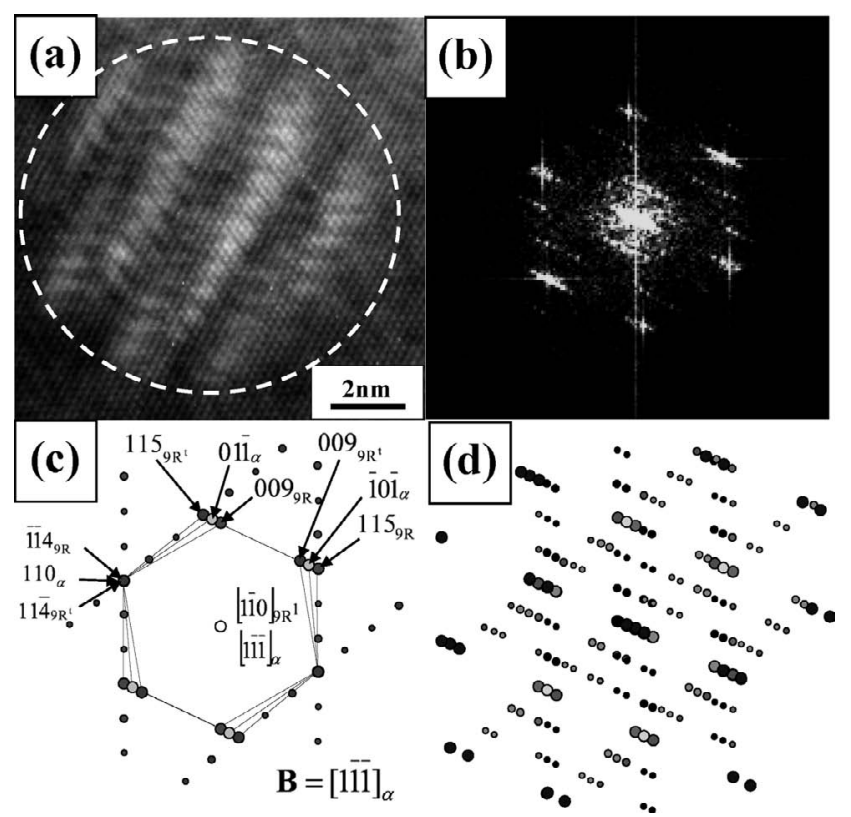

Fig. 5. (a) High resolution TEM image for the E2 steel aged at $700^{\circ} \mathrm{C}$ for $0.3 \mathrm{ks}$. (b) the Fourier transformed pattern of (a). (c) a simulated diffraction pattern of ferrite, $\alpha$, and two 9Rstructure variants. (d) a diffraction pattern illustrated by taking into account the occurrence of double reflections in (c). 
particles with striped contrasts and rod-shaped particles should be related to copper condensation, i.e. $\mathrm{Cu}$ precipitation. Figure 4(a) shows a high resolution TEM image of a spherical zone observed in Fig. 3(a). Figure 4(b) shows a Fourier transformed (FT) pattern of Fig. 4(a). The incident electron beam was parallel to the $[1 \overline{1} \overline{1}]_{\alpha}$ direction. It was confirmed that the spherical zone had bcc structure and was coherent with the matrix. Figure 5(a) is a high resolution TEM image of a spherical particle with striped contrast shown in Fig. 3(b). The incident electron beam was parallel to the $[1 \overline{1} \overline{1}]_{\alpha}$ direction. A dotted circle indicates the interface between the spherical particle and the matrix. Atomic arrangements of the spherical particle exhibited a herringbone type contrasts corresponding to multi-twinning. Twin planes were almost parallel to $\{110\}_{\alpha}$. Figure 5(b) shows a

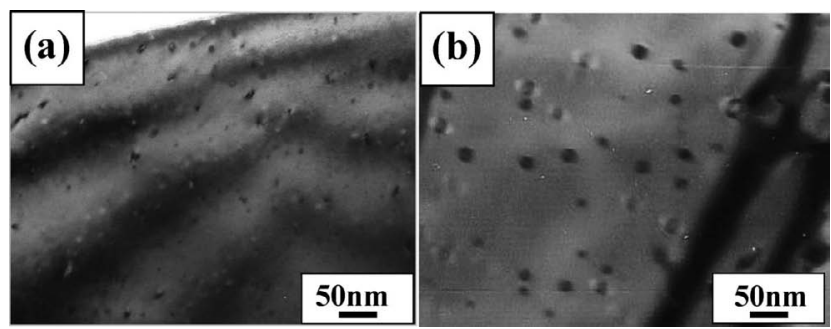

Fig. 6. TEM micrographs for the $\mathrm{E} 3$ steel aged at $700^{\circ} \mathrm{C}$ for (a) 0.3 and (b) $1.8 \mathrm{ks}$, respectively.
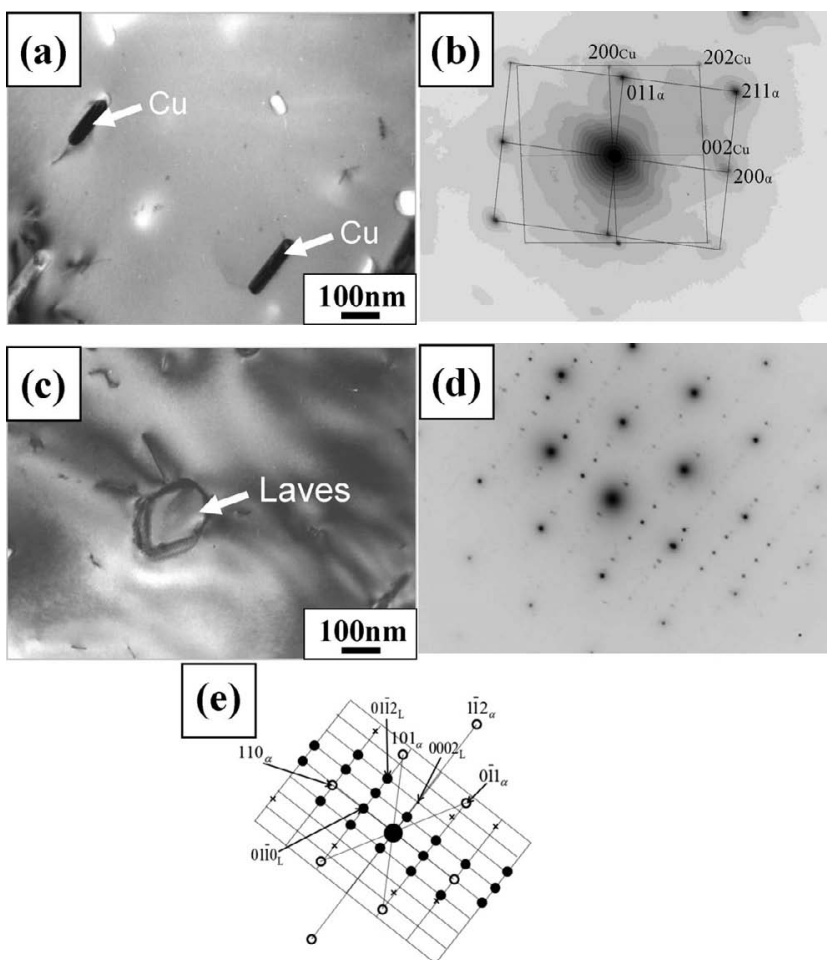

Fig. 7. Bright field image for formation of $\mathrm{Cu}$ particles in the $\mathrm{E} 3$ steel aged at $700^{\circ} \mathrm{C}$ for $86.4 \mathrm{ks}$. Selected area diffraction pattern taken from (a) is shown in (b). (c) Bright field image for formation of Laves phase in the $\mathrm{E} 3$ steel aged at $700^{\circ} \mathrm{C}$ for $86.4 \mathrm{ks}$. Selected area diffraction patterns taken from (a) is shown in (d). Key diagram of Fig. 7(d) is illustrated in (e). Solid circles and open circles in (e) correspond to diffraction spots of Laves phase and ferrite matrix, respectively. Subscript letters $\alpha$ and L denote ferrite matrix and Laves phase, respectively. Cross marks indicate double or triple reflections.
FT pattern of Fig. 5(a). Figure 5(c) shows simulated diffraction patterns of ferrite and two variants of 9R-structure with orientation relationship between ferrite and a 9R-structure variant as $[\overline{1} 11]_{\alpha} / /[\overline{1} 10]_{9 \mathrm{R}-\mathrm{Cu}}$ and $(\overline{1} \overline{1} 0)_{\alpha} / /(11 \overline{4})_{9 \mathrm{R}-\mathrm{Cu}}$. The diffraction simulation was carried out using the software, Desktop Microscopist, by the Lacuna Laboratories. In the diffraction simulation the 9R-structure variants hold twin relationship whose twin plane is $(\overline{1} \overline{1} 4)_{9 \mathrm{R}-\mathrm{Cu}}$, parallel to $(110)_{a}$. By taking account of double reflections in Fig. 5(c), a diffraction pattern in Fig. 5(d) is obtained. All spots (intensities) in the FT pattern in Fig. 5(b) can be explained by referring to Fig. 5(d). Thus, the particle in Fig. 5(a) is of 9R structure with twins whose twinning plane is parallel to $(\overline{1} 14)_{9 \mathrm{R}-\mathrm{Cu}} / /(110)_{\alpha}$. The 9R-Cu particles and the ferrite matrix were related by the orientation relationship: $[\overline{1} 11]_{\alpha} / /[\overline{1} 10]_{9 \mathrm{R}-\mathrm{Cu}}$ and $(\overline{1} \overline{1} 0)_{\alpha} / /(11 \overline{4})_{9 \mathrm{R}-\mathrm{Cu}}$, which was found in the previous studies. $^{17,18,23)}$

Figures 6(a) and 6(b) are the bright field images of E3 steel aged at $700^{\circ} \mathrm{C}$ for 0.3 and $1.8 \mathrm{ks}$, respectively. Spherical $\mathrm{Cu}$-rich zones finely dispersed in the matrix can be found in Fig. 6(a), where the maximum hardness was obtained in E3 steel. Coarsening of $\mathrm{Cu}$ particles was observed in Fig. 6(b). Rod shaped particles were found in
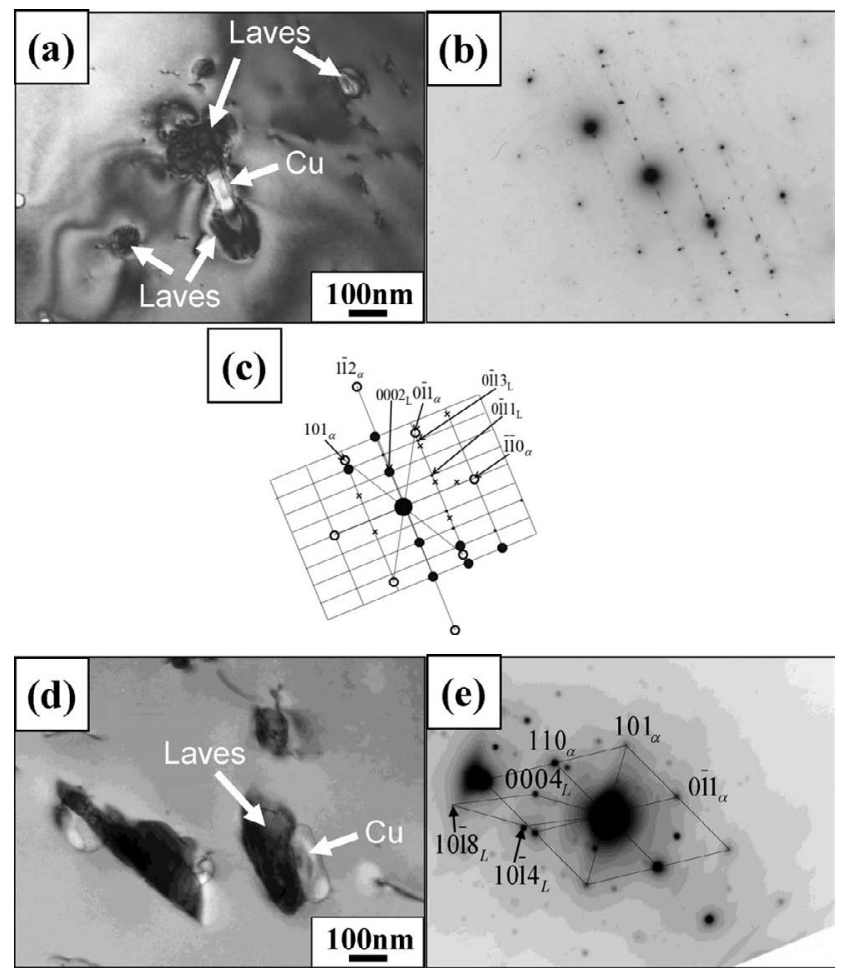

Fig. 8. (a) Bright field image of heterogeneous nucleation of Laves phase on $\mathrm{Cu}$ particle in $\mathrm{E} 3$ steel aged at $700^{\circ} \mathrm{C}$ for $86.4 \mathrm{ks}$. (b) Selected area diffraction pattern taken from (a). Key diagram of Fig. 8(b) is illustrated in (c). Solid circles and open circles in (c) correspond to diffraction spots of Laves phase and ferrite matrix, respectively. Subscript letters $\alpha$ and $\mathrm{L}$ denote ferrite matrix and Laves phase, respectively. Cross marks indicate double or triple reflections. (d) Bright field image of heterogeneous nucleation of Laves phase on $\mathrm{Cu}$ particle in $\mathrm{E} 3$ steel aged at $700^{\circ} \mathrm{C}$ for $86.4 \mathrm{ks}$. (e) Selected area diffraction patterns taken from (d). 
E3 steel aged at $700^{\circ} \mathrm{C}$ for $86.4 \mathrm{ks}$ as shown in Fig. 7(a). The SAD taken from Fig. 7(a) is shown in (b), revealing the rod shaped particles were fcc-Cu particles with near K-S orientation relationship to the ferrite matrix. Shape change of $\mathrm{Cu}$ particles from sphere to rod was also observed in E3 steel. Homogeneous nucleation of Laves phase ${ }^{32)}$ in the matrix can be found in Fig. 7(c). The SAD taken from Fig. 7(c) is shown in (d). Key diagram of Fig. 7(d) is illustrated in Fig. 7(e). The crystallographic orientation relationship between Laves phase and the matrix is as follows; $(1 \overline{1} 2)_{\alpha} / /$ $(0001)_{\mathrm{L}}$ and $(110)_{\alpha} / /(01 \overline{1} 0)_{\mathrm{L}}$, which is the same as that found in Fig. 2(d). Heterogeneous nucleation of Laves phase on $\mathrm{Cu}$ particles was also found as shown in Figs. 8(a) and 8(d). The SAD taken from Figs. 8(a) and 8(d) are shown in Figs. 8(b) and 8(e), respectively. Key diagram of Fig. 8(b) is illustrated in Fig. 8(c). The Laves phase particles nucleated on the edge or the side of rod-shaped $\mathrm{Cu}$ particles.

\section{Discussion}

\subsection{Hardness Change during Isothermal Aging}

The Hv of E1 and E2 steels after SST were the same as 138. The Hv of a binary $\mathrm{Fe}-18 \% \mathrm{Cr}$ alloy after SST was measured separately as 121 . Therefore, the amounts of solid solution hardening by $0.48 \% \mathrm{Nb}$ in E1 steel and $1.53 \% \mathrm{Cu}$ in E2 steel were $17 \mathrm{Hv}$. Increment in hardness by $0.48 \% \mathrm{Nb}$ $(=0.28 \mathrm{at} \% \mathrm{Nb})$ addition in a $18 \% \mathrm{Cr}$ steel (E1 steel) after SST was the same as that in a $18 \% \mathrm{Cr}$ steel with $1.53 \% \mathrm{Cu}$ $(=1.33 \mathrm{at} \% \mathrm{Cu})$ (E2 steel). The amount of $\mathrm{Nb}$ atoms, 0.28 at $\%$, in $\mathrm{E} 1$ steel is about one fifth of that of $\mathrm{Cu}$ atoms, 1.33 at $\%$, in E2 steel, implying that the effect of solid solution hardening by $\mathrm{Nb}$ atoms is five times greater than that by $\mathrm{Cu}$ atoms. Since the amount of solid solution hardening by additions of both $0.47 \% \mathrm{Nb}$ and $1.57 \% \mathrm{Cu}$ into a $18 \% \mathrm{Cr}$ steel (E3 steel) was $36 \mathrm{Hv}$, the effect of simultaneous addition of $\mathrm{Nb}$ and $\mathrm{Cu}$ atoms on $\mathrm{Hv}$ seems to almost follow additivity rule. This implies that solute $\mathrm{Nb}$ and $\mathrm{Cu}$ atoms in $\mathrm{E} 3$ steel exist in the ferrite matrix independently.

Although precipitation of Laves phase in E1 steel was observed during aging, age-hardening was hardly observed in E1 steel. Since formation of Laves phase consumes solute $\mathrm{Nb}$ atoms, an increase in hardness by the formation of Laves phase should accompany a decrease in hardness by loss of solution hardening by solute $\mathrm{Nb}$ atoms. For E1 steel, the effect of precipitation hardening was cancelled out by chance due to the solute depletion in the matrix. According to another experiment by authors, the change of $\mathrm{Hv}$ during aging at $700^{\circ} \mathrm{C}$ in a $18 \% \mathrm{Cr}$ steel with $0.87 \% \mathrm{Nb}$ was also measured and age hardening by precipitation of Laves phase was detected. It can be said that the balance between solid solution hardening and precipitation hardening will determine age-hardening processes of $\mathrm{Nb}$ added stainless steels.

Large increase in Hv during aging was observed in E2 and E3 steels due to formation of fine Cu-rich zones. The maximum hardness in E2 and E3 steels decreases with increasing in aging temperature, implying that volume fraction of $\mathrm{Cu}$ precipitates decreases or inter-particle distance of $\mathrm{Cu}$ precipitates increases with increasing in aging temperature. Since solubility of $\mathrm{Cu}$ in ferrite increases with increasing temperature, ${ }^{9,10)}$ volume fraction of $\mathrm{Cu}$ precipitates in $\mathrm{E} 2$ and $\mathrm{E} 3$ steels should be decreased in the higher temperature range. After onset of a decrease in $\mathrm{Hv}$, the $\mathrm{Cu}$ particles having 9R-structure were started to observe. This implies that the decrease in $\mathrm{Hv}$ could be related to not only an increase in the distance between the $\mathrm{Cu}$-rich zones by coarsening but also structural change of the zones from bec to $9 \mathrm{R}$-structure. Deformation mechanism of the steels is expected to change from the cutting of the zones to the Orowan-type or crossslip around $9 \mathrm{R}-\mathrm{Cu}$ particles. The change of $\mathrm{Hv}$ by the formation of $\mathrm{Cu}$-rich precipitates is governed by various factors, i.e., precipitate size, volume fraction, concentration and structure of the $\mathrm{Cu}$-rich zones/particles, which will be examined in future. It should be noted that onset of increase in $\mathrm{Hv}$ by the formation of $\mathrm{Cu}$-rich zones is retarded in $\mathrm{E} 3$ steel. Since the Laves phase was not observed in the early stage of formation of Cu-rich zones in E3 steel, it is considered that solute $\mathrm{Nb}$ atoms suppressed the formation of $\mathrm{Cu}$ rich zones.

\subsection{Retardation of $\mathrm{Cu}$ precipitation by Solute $\mathrm{Nb}$ Atoms}

Retardation of nucleation of $\mathrm{Cu}$-rich precipitates by solute $\mathrm{Nb}$ atoms was detected in all temperature ranges examined (by reference to Fig. 1). The $\mathrm{Cu}$ precipitation began with the formation of $\mathrm{Cu}$-rich solute zones in both E2 and $\mathrm{E} 3$ steels. The effect of solute $\mathrm{Nb}$ atoms on the formation of $\mathrm{Cu}$-rich solute zones will be discussed as follows.

The atom probe studies have shown that bcc $\mathrm{Cu}$-rich zones in binary $\mathrm{Fe}-\mathrm{Cu}$ alloy contained substantial amount of Fe. ${ }^{14,33,34)}$ Goodman et al. reported that nanometer sized $\mathrm{Cu}-$ rich zones contained approximately $50 \% \mathrm{Fe}^{14)}$ In commercial steels containing $\mathrm{Ni}, \mathrm{Mn}$ and $\mathrm{Al}$ bcc $\mathrm{Cu}$-rich zones in nanometer size contained relatively large amounts of $\mathrm{Fe}, \mathrm{Ni}$ and $\mathrm{Al}^{35)}$ Furthermore, the computer simulation with CahnHilliard diffusion equation revealed that a nucleus of $\mathrm{Cu}-$ rich precipitate contained large amount of $\mathrm{Fe}$ in the early stage of Cu precipitation. ${ }^{36)}$ Therefore, bcc $\mathrm{Cu}$-rich spherical zones observed in the early stage of aging in E3 steel might contain substitutional constitutive element, such as $\mathrm{Fe}, \mathrm{Cr}$ and $\mathrm{Nb}$. However, the inclusion of $\mathrm{Nb}$ atoms in the $\mathrm{Cu}$-rich zones seems to be unfavorable and $\mathrm{Nb}$ atoms should diffuse outward from the zones during nucleation of the zones for the following reasons. The interaction parameter, $\mathrm{L}$, of thermodynamic expression for regular solutions in a binary system indicates how two different atoms will interact in each other. The $\mathrm{L}$ in $\mathrm{X}-\mathrm{Y}$ binary system is defined as $\mathrm{L}=\mathrm{z} \mathrm{N}_{\mathrm{A}}\left(\mathrm{E}_{\mathrm{XY}}-1 / 2\left(\mathrm{E}_{X X}+\mathrm{E}_{Y Y}\right)\right)$, where $\mathrm{z}$ is coordination number, $N_{A}$ is Avogadro's number and $E_{X Y}$ is bond energy per atom pair between $\mathrm{X}$ and $\mathrm{Y}$ atoms, $\left(\mathrm{E}_{\mathrm{XX}}\right.$ and $\mathrm{E}_{\mathrm{YY}}$ are also defined as that of $E_{X Y}$ ). If $L<0$, the atoms in the solution prefer to be surrounded by atoms of the opposite type, while if $\mathrm{L}>0$, the atoms prefer to be surrounded by atoms of their own kind. The interaction parameter of bcc phase in $\mathrm{Fe}-\mathrm{Cu}$ system, ${ }^{\text {bcc }} \mathrm{L}_{\mathrm{FeCu}}$, was reported as ${ }^{\mathrm{bcc}} \mathrm{L}_{\mathrm{FeCu}}=(41033-6.022 \times \mathrm{T})$ $\mathrm{J} / \mathrm{mol}$, where $\mathrm{T}$ is temperature. ${ }^{37)}$ Another ${ }^{\mathrm{bcc}} \mathrm{L}_{\mathrm{FeCu}}$ parameter was also suggested as ${ }^{\text {bcc }} \mathrm{L}_{\mathrm{FeCu}}=(39257.976-4.1498304 \times \mathrm{T})$ $\mathrm{J} / \mathrm{mol}{ }^{38)}$ Therefore, the values of ${ }^{\text {bcc }} \mathrm{L}_{\mathrm{FeCu}}$ at $700^{\circ} \mathrm{C}$ in each case are calculated as 35174 and $35220 \mathrm{~J} / \mathrm{mol}$, respectively. On the other hand, interaction parameter of bcc phase in $\mathrm{Nb}-\mathrm{Cu}$ system, ${ }^{\text {bcc }} \mathrm{L}_{\mathrm{NbCu}}$, was reported as $49480.18 \mathrm{~J} / \mathrm{mol}^{39)}$ Since the ${ }^{b c c} \mathrm{~L}_{\mathrm{NbCu}}$ is much larger than the ${ }^{\mathrm{bcc}} \mathrm{L}_{\mathrm{FeCu}}$, the existence of $\mathrm{Nb}$ atoms in the $\mathrm{Cu}$-rich zones is more unfavorable 
than the case of $\mathrm{Fe}$ atoms. Furthermore, since inclusion of $\mathrm{Nb}$ atoms in a $\mathrm{Cu}$-rich zone would increase the strain energy for nucleation of the zones, $\mathrm{Nb}$ atoms should be away from the zones. Atomic radii in angstrom of $\mathrm{Fe}, \mathrm{Cr}, \mathrm{Cu}$ and $\mathrm{Nb}$ atoms are $1.241,1.249,1.278$ and 1.426 , respectively. ${ }^{40)}$ The atomic radius of $\mathrm{Nb}$ is much larger than those of the others. Since atomic radius of $\mathrm{Cu}$ is a little larger than that of $\mathrm{Fe}$, lattice parameter of the bcc $\mathrm{Cu}$-rich zone would be larger than that of the matrix which consists of mainly Fe atoms, resulting in a misfit strain at the interface. If $\mathrm{Nb}$ atoms were included in the bcc $\mathrm{Cu}$-rich zone, lattice parameter of the zone would be more increased and strain energy barrier for the zone nucleation should increase. Therefore, it has been shown that inclusion of $\mathrm{Nb}$ atoms in the bcc $\mathrm{Cu}$-rich zones is not preferable for the zone nucleation from the two points of view, i.e., the interaction parameter, L, and the strain energy for nucleation of the zones.

In the process of $\mathrm{Cu}$-rich zone formation, therefore, outward diffusion of $\mathrm{Nb}$ atoms is needed to occur. The outward diffusion of $\mathrm{Nb}$ atoms from the $\mathrm{Cu}$-rich zones should lead to formation of $\mathrm{Nb}$-rich zones around them. Actually, the $\mathrm{Nb}$-rich Laves phase nucleated on the $\mathrm{Cu}$-rich precipitates as shown in Fig. 8. The diffusion coefficient of $\mathrm{Nb}$ in ferrite is substantially smaller than that of $\mathrm{Cu}$ in ferrite. ${ }^{41)}$ For example, according to the diffusion coefficients of $\mathrm{Cu}$ and $\mathrm{Nb}$ atoms in ferrite, migration distances of $\mathrm{Cu}$ and $\mathrm{Nb}$ atoms by a random walk at $700^{\circ} \mathrm{C}$ for $10 \mathrm{~s}$ will be 18 and $4 \mathrm{~nm}$, respectively. The migration distance of $\mathrm{Nb}$ atoms is about one-fifth of that of $\mathrm{Cu}$ atoms. The slow diffusion of $\mathrm{Nb}$ atoms would retard the nucleation of the $\mathrm{Cu}$-rich zones. Outward diffusion of $\mathrm{Fe}$ and $\mathrm{Cr}$ atoms from the $\mathrm{Cu}$-rich zones would also occur. Since their diffusions in E2 and E3 steels are expected to be almost the same in terms of diffusion rate, they are little relation to the retardation of the zone formation.

\section{Conclusions}

The formations of $\mathrm{Cu}$ precipitate in $18 \% \mathrm{Cr}-1.5 \% \mathrm{Cu}$ stainless steels without and with $0.5 \% \mathrm{Nb}$ are summarized as follows.

(1) Formation of $\mathrm{Cu}$ precipitates in ferrite began with nucleation of bcc $\mathrm{Cu}$-rich spherical zones. The bcc $\mathrm{Cu}$-rich zones first transformed into multi-twinned 9R structure and then changed to fcc structure associated with shape change into rod.

(2) The initial increase in Hv during aging was caused by the formation of fine spherical $\mathrm{Cu}$-rich zones. The decrease in $\mathrm{Hv}$ after the increase in $\mathrm{Hv}$ was probably due to not only coarsening of the $\mathrm{Cu}$-rich zones but also structural change of the zones from bcc to 9R-structure. The onset of increase in $\mathrm{Hv}$ by the formation of $\mathrm{Cu}$-rich zones was retarded by solute $\mathrm{Nb}$ atoms.

(3) Solute $\mathrm{Nb}$ atoms delayed formation of $\mathrm{Cu}$-rich zones in a ferritic stainless steel. Since the inclusion of $\mathrm{Nb}$ atoms in the $\mathrm{Cu}$-rich zones is unfavorable, outward diffusion of $\mathrm{Nb}$ atoms from the zones is needed for nucleation of the zones. Since the diffusion of $\mathrm{Nb}$ atoms in a ferrite matrix is substantially slower than that of $\mathrm{Cu}$ atoms, the formation of the $\mathrm{Cu}$-rich zones is delayed by slow diffusion of $\mathrm{Nb}$ atoms.

(4) Laves phase, $\mathrm{Fe}_{2} \mathrm{Nb}$, formed in $\mathrm{Nb}$ added ferritic stainless steels during aging. Some of Laves phase particles nucleated on $\mathrm{Cu}$-rich precipitates, implying that outward diffusion of $\mathrm{Nb}$ atoms from $\mathrm{Cu}$-rich zones occurred.

\section{Acknowledgments}

The authors wish to express their sincere thanks to the Integrated Center for Sciences (INCS), Ehime University for use of TEM (JEM2100).

\section{REFERENCES}

1) K. Nakashima, Y. Futamura, T. Tsuchiyama and S. Takaki: Tetsu-toHagané, 89 (2003), 524.

2) T. Yokoi, M. Takahashi, N. Maruyama and M. Sugiyama: J. Mater. Sci., 36 (2001), 5757.

3) K. Kishida: Nippon Steel Tech. Rep., 64 (1995), 33.

4) T. Yokoi, M. Takahashi, N. Maruyama and M Sugiyama: Nippon Steel Tech. Rep., 91 (2005), 49.

5) N. Maruyama, M. Sugiyama, T. Hara and H. Tamehiro: Mater. Trans. JIM, 40 (1999), 268.

6) K. Kishida and O. Akisue: Tetsu-to-Hagané, 76 (1990), 759

7) Y. Okitsu, T. Ukena and M. Oda: Tetsu-to-Hagané, 81 (1995), 739.

8) M. Morita, K. Sato and Y. Hosoya: Tetsu-to-Hagané, 80 (1994), 48.

9) T. B. Massalski, H. Okamoto, P. R. Subramanian and L. Kacprzak: BINARY ALLOY PHASE DIAGRAM 2nd ed., ASM International, Ohio, (1990), 1408.

10) G. R. Speich and M. Cohen: Trans. Met. Soc. AIME, 218 (1960), 1050.

11) E. Hornbogen and R. C. Glenn: Trans. Met. Soc. AIME, 218 (1960), 1064.

12) S. K. Lahiri, D. Chandra, L. H. Schwartz, and M. E. Fine: Trans. Met. Soc. AIME, 245 (1969), 1865.

13) S. R. Goodman, S. S. Brenner and J. R. Low, Jr.: Metall. Trans., 4 (1973), 2363.

14) S. R. Goodman, S. S. Brenner and J. R. Low, Jr.: Metall. Trans., 4 (1973), 2371.

15) K. Osamura, H. Okuda, M. Takashima, K. Asano and M. Furusaka: Mater. Trans. JIM, 34 (1993), 305.

16) S. Pizzini, K. J. Roberts, W. J. Phythian, C. A. English and G. N. Greaves: Philos. Mag. Lett., 61 (1990), 223.

17) P. J. Othen, M. L. Jenkins and G. D. W. Smith: Philos. Mag. A, 70 (1994), 1.

18) P. J. Othen, M. L. Jenkins, G. D. W. Smith and W. J. Phythian: Philos. Mag. Lett., 64 (1991), 383.

19) U. Dahmen, P. Ferguson and K. H. Westmacott: Acta Metall., 32 (1984), 803.

20) E. Hornbogen: Acta Metall., 10 (1962), 525.

21) B. Soylu and R. W. K. Honeycombe: Mater. Sci. Technol., 7 (1991), 137.

22) H. R. Habibi Bajguirani, C. Servant and G. Cizeron: Acta Metall. Mater., 41 (1993), 1613.

23) H. R. Habibi Bajguirani and M. L. Jenkins: Philos. Mag. Lett., 73 (1996), 155

24) H. R. Habibi Bajguirani: Mater. Sci. Eng., A338 (2002), 142.

25) M. Murayama, Y. Katayama and K. Hono: Metall. Mater. Trans. A, 30A (1999), 345.

26) M. Httestrand, J.-O. Nilsson, K. Stiller, P. Liu and M. Andersson: Acta Mater., 52 (2004), 1023.

27) A. Yamamoto, T. Ashiura and E. Kamisaka: Corros. Eng., 35 (1986), 448.

28) N. Ookubo, S. Nakamura, M. Yamamoto and K. Miyakusu: Nisshin Steel Tech. Rep., 77 (1998), 69.

29) N. Fujita, K. Ohmura, M. Kikuchi, T. Suzuki, S. Funaki and I. Hiroshige: Scr. Mater., 35 (1996), 705.

30) N. Fujita, K. Ohmura and A. Yamamoto: Mater. Sci. Eng., A351 (2003), 272.

31) H. Yan, H. Bi, X. Li and Z. Xu: Mater. Charact., 60 (2009), 204.

32) T. Sawatani, S. Minamino and H. Morikawa: Tetsu-to-Hagané, 65 (1979), 64

33) M. K. Miller, B. D. Wirth and G. R. Odette: Mater. Sci. Eng., A353 (2003), 133.

34) C. Zhang, M. Enomoto, T. Yamashita and N. Sano: Metall. Mater. Trans. A, 35A (2004), 1263.

35) R. P. Kolli and D. N. Seidman: Acta Mater., 56 (2008), 2073.

36) T. Nagano and M. Enomoto: Scr. Mater., 55 (2006), 223.

37) J. Miettinen: Calphad, 22 (1998), 275.

38) A. Caro, P. E. A. Turchi, M. Caro and E. M. Lopasso: J. Nucl. Mater., 336 (2005), 233.

39) M. Hämäläinen, K. Jääskeläinen, R. Luoma, M. Nuotio, P. Taskinen and O. Teppo: Calphad, 14 (1990), 125.

40) D. R. Askeland and P. P. Phulé: Essentials of Materials Science and Engineering, Thomson, Canada, (2004), 567

41) Kinzoku data book (revision 4), ed. by Japan Inst. of Metals, Maruzen, Tokyo, (2004), 21. 